\title{
Ciber agricultura familiar en tiempo de COVID 19, contexto Guano- Ecuador
}

\begin{abstract}
Family cyber agriculture in time of COVID 19, Guano- Ecuador context
\end{abstract}
Carmen Elena Mantilla Cabrera. ${ }^{1}$, Daniela Alejandra Zambrano Ríos. ${ }^{2}$, Juan Eduardo León Ruiz. ${ }^{3}$ \& Vicente Javier Parra León. ${ }^{4}$

Recibido: 29-06-2021 / Revisado: 09-07-2021 /Aceptado: 28-07-2021/ Publicado: 05-08-2021

\begin{abstract}
.
DOI: https://doi.org/10.33262/concienciadigital.v4i3.1.1839

Introduction. The COVID-19 pandemic generated a socio-economic crisis, making traditional transactions impossible due to quarantine and social distancing, it was necessary to adapt to new forms and family farming is no exception. Digital platforms have supported commercialization involving different actors, electronic commerce for farmers allowed a great technological leap, and an online market was created in Ecuador that contributed to creating a sustainable local food system of mutual benefit between farmer and consumer. Objective. Propose electronic commerce for peasant family agriculture in the Guano Canton in the context of the Covid 19 pandemic. Methodology. The main business models suitable for the commercialization of agricultural products of the Guano Canton were analyzed, the behavior of consumers and producers in virtual stores was evaluated in the framework of the COVID 19 pandemic, a business model was

\footnotetext{
${ }^{1}$ Escuela Superior Politécnica de Chimborazo, Facultad de Recursos Naturales, Grupo de Investigación en Seguridad Telemática (SEGINTE). Riobamba, Ecuador. carmen.mantilla@espoch.edu.ec, ORCID: https://orcid.org/0000-0001-5422-7073

2Investigadora independiente, Riobamba, Ecuador danizambrano_r@hotmail.com, ORCID: https://orcid.org/0000-0003-1132-7482

3Escuela Superior Politécnica de Chimborazo, Facultad de Recursos Naturales, Riobamba, Ecuador juan.leon@espoch.edu.ec https://orcid.org/ ORCID: 0000-0002-5304-7959

${ }^{4}$ Escuela Superior Politécnica de Chimborazo, Facultad de Recursos Naturales, Riobamba, Ecuador vicente.parra@espoch.edu.ec. ORCID: https://orcid.org/0000-0002-7632-2474
} 
defined for the commercialization of agricultural products and derived from Canton Guano. Results. The study determined that for the Guano Canton the business model is B2C, business to consumer, with a classic merchant pattern. In addition, the design of the web page is presented based on the results of the investigation, with a user profile and an administrator profile with their respective menus for their functionality to support family farming in the Guano canton. Conclusion. The B2C business model for electronic commerce in the Guano canton allowed direct transactions between producer and final consumer. The platform "one click from your harvest" guarantees the management of a virtual agenda where the producers associated with their respective products offered are listed, guaranteeing the producer virtual marketing of their products at a fair price through the standardization of prices, in addition, this achieved that These products are part of the family baskets since the application of the Field School ensures the quality and quantity of production to comply with food sovereignty.

Keywords: peasant family farming, farming, electronic commerce, COVID 19, Guano.

\section{Resumen.}

Introducción. La pandemia por la COVID-19, generó una crisis socio económica, imposibilitando las transacciones tradicionales por la cuarentena y el distanciamiento social, fue necesario acoplarnos a nuevas formas y la agricultura familiar no es la excepción. Las plataformas digitales han apoyado a la comercialización implicando diferentes actores, el comercio electrónico para agricultores permitió un gran salto tecnológico, ya se creó un mercado online en Ecuador que contribuyó a crear un sistema de alimentación local sostenible de beneficio mutuo entre agricultor y consumidor. Objetivo. Proponer comercio electrónico para la agricultura familiar campesina del Cantón Guano en el contexto de la pandemia Covid 19. Metodología. Se analizó los principales modelos de negocio aptos para la comercialización de productos agrícolas del Cantón Guano, se evaluó el comportamiento de consumidores y productores en tiendas virtuales en el marco de la pandemia COVID 19, se definió un modelo de negocio para la comercialización de productos agrícolas y derivados del Cantón Guano. Resultados. El estudio determinó que para el Cantón Guano el modelo de negocio es del tipo B2C, empresa a consumidor, con un patrón comerciante clásico. Además, se presenta el diseño de la página web en base a los resultados de la investigación, con un perfil de usuario y el de administrador con sus respectivos menús para su funcionalidad apoyar a la agricultura familiar en el cantón Guano. Conclusión. El modelo de negocio B2C para comercio electrónico en el cantón Guano permitió transacciones directas entre productor y consumidor final. La plataforma "a un clic de tu cosecha" garantiza el manejo de una agenda virtual donde constan los productores asociados con sus respectivos productos ofertados, garantizando al productor comercialización virtual de sus productos a un precio justo mediante la estandarización de precios, además este logró que estos productos formen parte de las canastas familiares ya que la aplicación de la Escuela de Campo asegura la calidad y cantidad de producción para cumplir la soberanía alimentaria. 
Palabras claves: agricultura familiar campesina, agricultura, comercio electrónico, COVID 19, Guano.

\section{Introducción.}

El internet ha evolucionado de tal forma que ha potencializado las transmisiones de forma rápida y efectiva para que los usuarios puedan acceder a bienes y servicios para realizar transacciones de negocios en forma digital, esta forma de negocio posee grande ventajas como el ahorro de recursos y tiempo al mismo tiempo puede vencer la limitación geográfica entre otras (Perdigón, 2018).

Latinoamérica se considera la segunda región con mayor crecimiento anual en ventas y campañas de marketing digital en las últimas décadas, lo que dio paso a la innovación en la creación de modelos de negocio, utilizando múltiples aplicaciones como portales, buscadores de información y las tiendas de comercio electrónico (e-commerce) como canal seguro de transacciones entre vendedores y compradores (Nielsen, 2018).

Es aquí donde la ciber agricultura engloba a más de los servicios agrícolas que se prestan a los ciudadanos en comunidades rurales mediante las TICs varios productos, servicios agrícolas y de alimentación ofertadas por organizaciones gubernamentales y no gubernamentales (FAO, 2018).

Los consumidores ecuatorianos en su mayoría realizaban sus compras en forma física, se estima un aproximado de un 5\% que utilizaban los medios digitales, lo que la pandemia ha cambiado ya que este fue el motivo por lo que, un mayor número de personas hacen uso de plataformas digitales (Rodríguez, 2020).

En este contexto en Ecuador debido a la pandemia por el COVID-19 el comercio electrónico provee un valor añadido para mantener el ritmo económico, pues los pequeños y medianos productores agrícolas tienen una capacidad logística insatisfecha para la comercialización de sus productos ya que debido a las restricciones de confinamiento no pudieron realizarlas de la forma tradicional (Esteves, 2020).

Ante el cierre de plazas y mercados y medios de expendio por la crisis sanitaria por la pandemia del SARS COVID-19 (Sandoval 2020), los productores no han encontrado canales de comercialización alternativos a los tradicionales, afectando su cosecha y pérdidas en su inversión de producción, limitando aún más el acceso a los alimentos por parte de la población implicando una disminución en la calidad de vida de productores y acrecentando las brechas entre el campo y la cuidad.

Los agricultores ecuatorianos hasta antes de la llegada del coronavirus solo habían utilizado las tecnologías de la información y la comunicación como la radio, la televisión y recientemente los relacionados a los teléfonos móviles, se necesitan abrir nuevos mercados y crear nuevas oportunidades de trabajo promoviendo la calidad de sus productos y fortalecer su competitividad a través del comercio por internet. 
El cantón Guano tiene pequeños y grandes productores agrícolas cuyos productos son el autoconsumo y comercialización, en el último año 2020 por la pandemia la comercialización bajo en un $90 \%$ ocasionando grandes pérdidas economías y una disminución de nivel socioeconómico. Por lo anteriormente mencionado se crea la necesidad de diseñar una plataforma de comercio electrónico como un mecanismo de marketing que se constituya en una herramienta adecuada de comercialización para la agricultura familiar campesina (Comunicación, 2021).

Entonces, para solucionar los problemas que se han presentado a los productores en la comercialización en la pandemia se genera la propuesta y puesta en ejecución del comercio electrónico para la agricultura familiar campesina del Cantón Guano para fortalecer la organización campesina y garantizar la comercialización de la producción agropecuaria en cantidad y calidad.

\section{Metodología.}

\section{A. CARACTERÍSTICAS DE GUANO}

EL hermoso cantón Guano está ubicado al norte de la Provincia de Chimborazo a 2683 msnm, limitado al norte en la Provincia de Tungurahua, al sur con el Cantón Riobamba; al este con el río Chambo; y al oeste, con el Cantón Riobamba y una pequeña parte de la Provincia de Bolívar. Está conformado por nueve Parroquias rurales: Guanando, La Providencia, San Andrés, San Gerardo, San Isidro de Patulu, San José de Chazo, Santa Fe de Galán y Valparaíso y dos parroquias urbanas: La Matriz y El Rosario (CESA, 2019).

La Figura 1, presenta las actividades económicas, se puede observar que las actividades agrícolas, ganaderas, de silvicultura y pesca son las que conllevan mayor PEA, representando el $43 \%$, seguida por las industrias manufactureras con el $14 \%$, el comercio con el $10 \%$ y la construcción, cada una con el $9 \%$, siendo las más relevante, pero existen otras actividades que dinamizan la actividad económica cantonal con porcentajes inferiores al 7\% como: el transporte, administración pública y defensa; actividades de los hogares como empleadores, enseñanza, entre otras (CESA, 2019).

\section{Figura 1}

Economía de Guano ACTIVIDADES ECONOMICAS DE GUANO

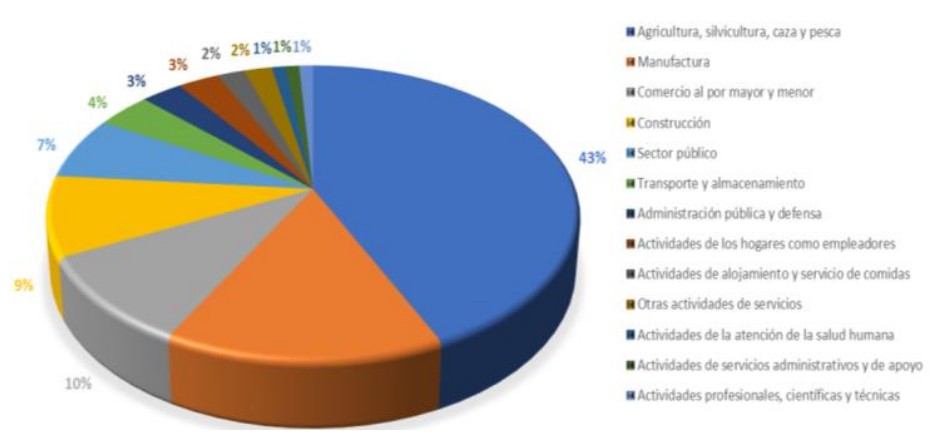

Fuente: Elaboración propia. 
Guano está conformado por 2 Parroquias urbanas y 9 rurales, están sujetas a la jurisdicción del Ilustre Municipalidad de Guano.

\section{Línea Base de los Productos y Canales de Comercialización}

Las actividades económicas que se destacan en la Provincia de Chimborazo son la agricultura, ganadería, silvicultura y pesca. La producción de la papa tiene el mayor volumen en la Provincia, seguido del tomate riñón, caña de azúcar, choclo, haba tierna y cebada.

La Figura 2, se muestra el uso de tierras cantón de Guano, como se puede observar el $42 \%$ corresponde a pastizales, el $40 \%$ a mosaicos agrícolas y el $18 \%$ a monocultivos (CESA, 2019).

\section{Figura 2}

Uso de tierras de Guano

Uso de tierras de Guano

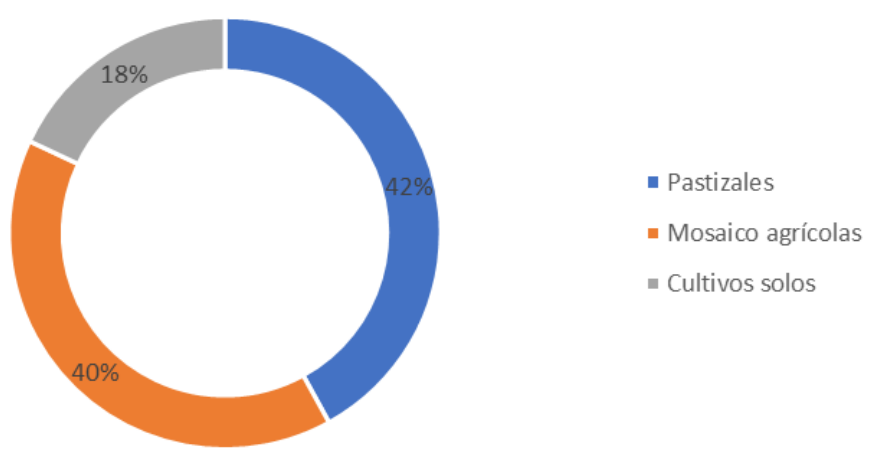

Fuente: Elaboración propia.

La Figura 3, muestra que la mayor superficie en hectáreas para cultivos se concentra en San Andrés y San José de Chingazo con un 17\%, seguido por Santa Fe de Galán y El Rosario con un $16 \%$ y $10 \%$ respectivamente.

\section{Figura 3}

Superficie de cultivo por parroquias

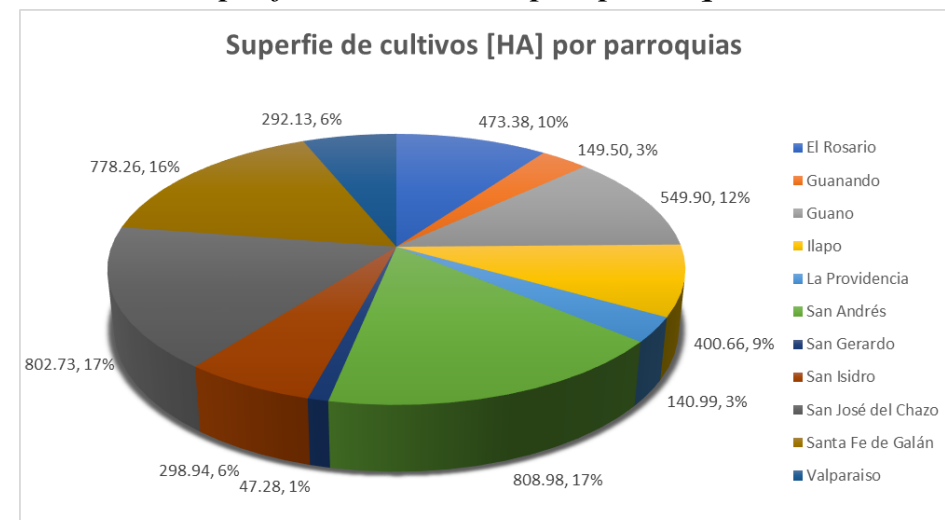

Fuente: Elaboración propia. 
Los cultivos con más alta producción de rendimiento y producción son en su orden, el maíz suave (seco y fresco), la papa, la cebolla blanca en rama y el haba, precisamente los cultivos que se asientan entre los 2.600 y $3.300 \mathrm{msnm}$

En las parroquias principalmente Ilapo y Santa Fe de Galán se comercializa la cebolla blanca, papa, habas se dirigen hacia los mercados de Tungurahua: 70\% cantón Mocha y Mercado Mayorista de Ambato; y el otro 30\% hacia mercados de Riobamba. En las Parroquias principalmente San Andrés, San Isidro, Guano se comercializan las papas, hortalizas (zanahoria) se dirigen hacia los mercados de Tungurahua: 50\% cantón Mocha y mercado Mayorista de Ambato y el otro 50\% hacia mercados de Riobamba.

En la Provincia principalmente San José de Chazo, Ilapo y Valparaiso se comercializan maíz amarillo seco y fresco, arveja y hortalizas se dirigen hacia mercados de Tungurahua: 50\% Cantón Mocha y Mercado Mayorista de Ambato el otro 50\% hacia mercados de Riobamba.

En las Parroquias principalmente San Andrés, San Isidro y Guano se comercializan lácteos $60 \%$ hacia procesadoras de Chimborazo, Cañar Azuay y el otro 40\% hacia procesadoras de Cotopaxi y Pichincha (CESA 2019).

\section{B. APLICACIÓN DE ENCUESTAS A ACTORES}

Se realizó entrevistas al personal técnico y administrativo de la Unidad de Emprendizajes y Emprendimientos, así como a presidentes y técnicos de las Juntas Parroquiales y presidentes de las comunidades con el propósito de conocer oferta y demanda en sus producciones.

La encuesta que consta de 14 preguntas en base al problema se socializó el personal técnico y administrativo del GAD y luego se aplicó en campo a los productores en base a un listado de productores entregados por las Juntas Parroquiales, mediante muestreo es probabilístico de pequeños grupos de las comunidades en forma de selección aleatoria simple para que todos en la comunidad tengan la misma oportunidad de ser seleccionados y encuestados.

La Figura 4, muestra el porcentaje de encuestados aleatoriamente en las parroquia del Cantón Guano de forma presencial, como se puede observar se encuesto en la Parroquia Guanando al $5 \%$ de sus agricultores, en la Parroquia Ilapo el $15 \%$, en la Parroquia La Providencia el 10\%, en la Parroquia San Gerardo de Pacaicahuan el $4 \%$, en la Parroquia San Andrés el $18 \%$, en la Parroquia San Isidro de Patulú el $27 \%$, en la Parroquia San José de Chazo el $9 \%$, en la Parroquia Valparaíso el $8 \%$, en La Matriz ( Guano) el 3, en la Parroquia Santa Fe de Galán se realizó la encuesta en menos del 3\%, es importante mencionar que los encuestados tenían recelo en compartir su información ya que se pronunciaban que la información compartida iba a ser mal utilizada en quitarles los beneficios sociales. 


\section{Figura 4}

Porcentaje de encuestados por parroquias

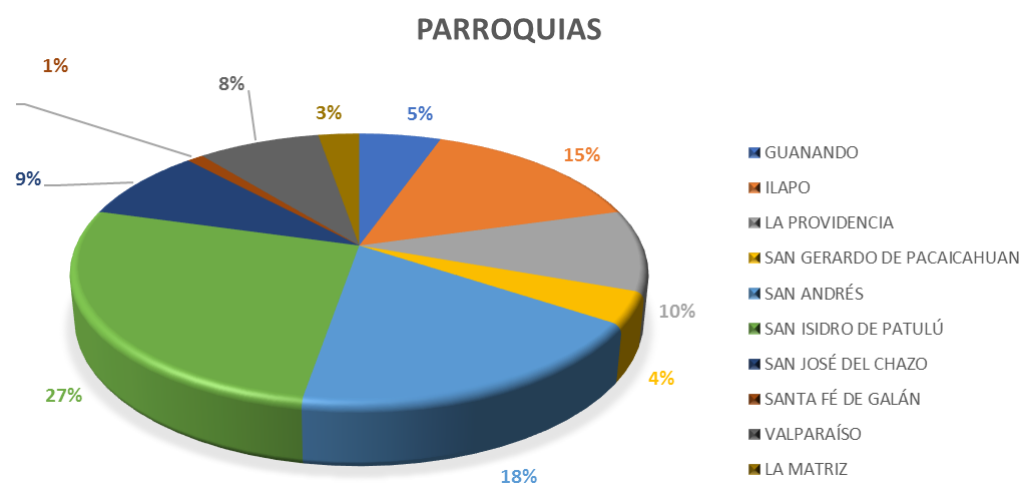

Fuente: Elaboración propia.

Con el acompañamiento de los presidentes de las juntas parroquiales del Cantón Guano se procedió a realizar la visita a los agricultores para levantar la información por medio de las encuestas cuyo resultado en el número de encuestados por comunidad se detalla a continuación, en la Parroquia Ilapo en la Comunidad de San Patricio de Pusniag se tuvo el 9\% de agricultores encuestados, en la Comunidad Saguazo la Unión el $13 \%$ de agricultores fueron encuestados, en la Parroquia San Gerardo en el barrio La Magdalena se tuvo el $4 \%$ de agricultores encuestados, en la Parroquia San Andrés, en las Comunidades La Silveria con el $11 \%$ y Calshi con el $22 \%$ fue el total de agricultores encuestados por Parroquia. en la Parroquia San Isidro la comunidad Tutupala con el 4\% de encuestados, San Francisco con el $3 \%$ de agricultores encuestados, en Santa Rosa y Asaco Grande el $27 \%$ de agricultores fueron los encuestados, finalmente en la Matriz, en Chingazo Alto el 5\% de los agricultores fueron encuestados como se muestra en la Figura 5 .

\section{Figura 5}

Número de encuestados por comunidades COMUNIDADES
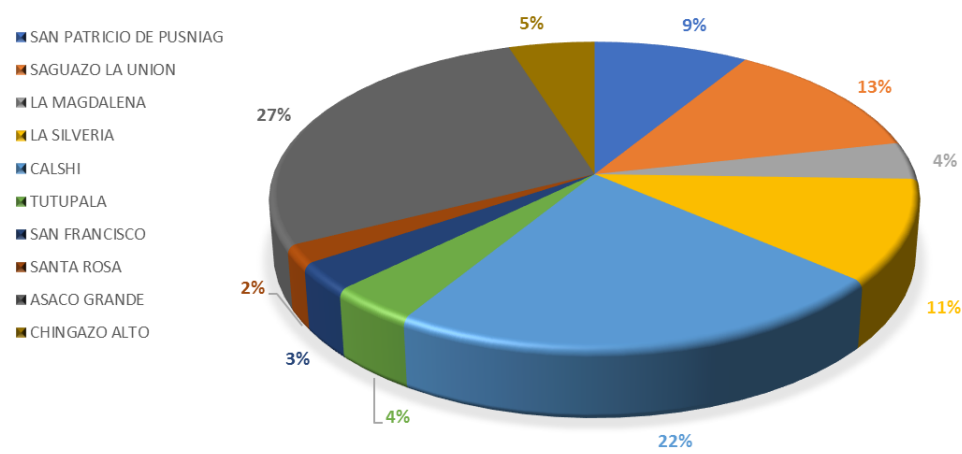

Fuente: Elaboración propia. 
De los encuestados en la Figura 6, se puede observar que el $79 \%$ de los encuestados se dedican a la producción agropecuaria.

\section{Figura 6}

Dependencia económica en Producción Agropecuaria

\section{SU ECONOMIA DEPENDE DE LA PRODUCCION AROPECUARIA}

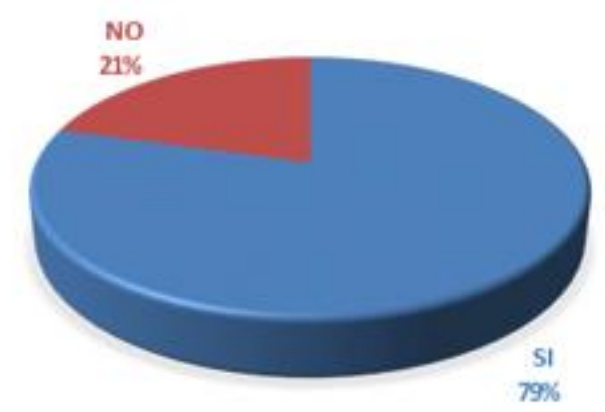

Fuente: Elaboración propia.

También se puede observar en la Figura 7 que el 57\% corresponde a grandes productores ya que tienen una tenencia mayor a $16000 \mathrm{~m}^{2}$, los medianos productores son el $10 \%$ considerado a una superficie comprendida entre 10000 y $16000 \mathrm{~m}^{2}$ y los pequeños productores representan el $33 \%$ de los agricultores encuestados con tenencias de superficies menores a $10000 \mathrm{~m}^{2}$.

\section{Figura 7}

Tipo de productor

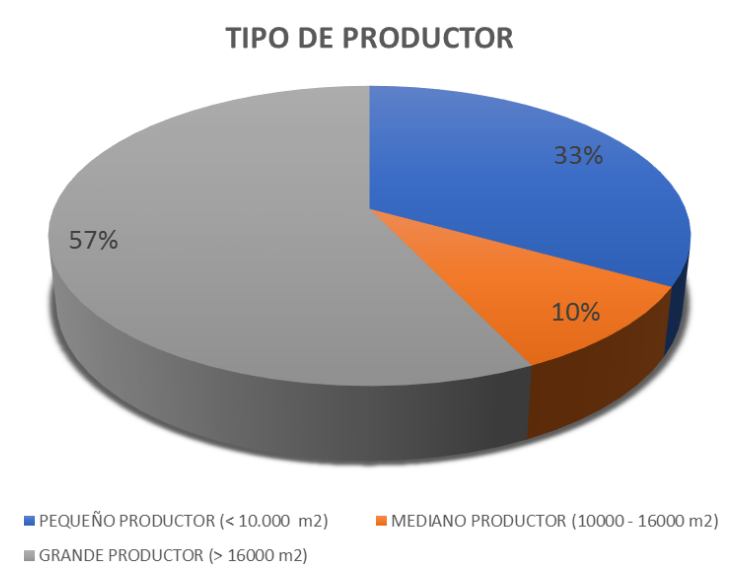

Fuente: Elaboración propia.

C. ANALISIS DE PRÁCTICAS AGROECOLÓGICAS EN LA AGRICULTURA FAMILIAR EN EL CANTÓN GUANO.

En el Cantón Guano el 52\% de los agricultores tienen conocimiento básico sobre la agroecología, y la información suscrita en el PDOT indica que las Parroquias San Isidro, Guanando, San José de Chazo, San Gerardo evidencian el $48 \%$ de agricultores que buscan 
impulsar el desarrollo en manejo de huertos familiares mediante prácticas agroecológicas, como se puede observar en la Figura 8.

También se puede observar que el $64 \%$ de los agricultores encuestados no usan prácticas agroecológicas y corresponden a las parroquias, San Andrés, La Matriz, El Rosario, Santa Fe de Galán, Valparaíso, Ilapo no practican el manejo de huertos familiares mediante prácticas agroecológicas:

El 91\% de la población tienen interés en la agroecología, ya que, según CLACSO, 2021, la agricultura familiar campesina en el Ecuador es la principal fuente de ingresos para la población rural, más aún en la pandemia donde no han dejado de producir para mantener abastecidos a los habitantes es lo que ha despertado en los agricultores la iniciativa en producir alimentos sanos y confiables para el consumidor.

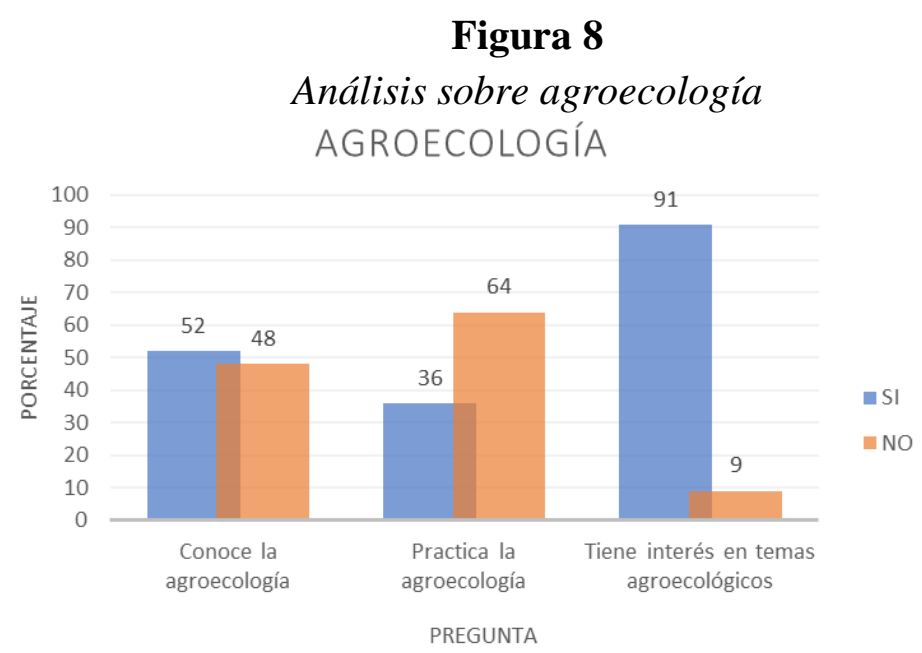

Fuente: Elaboración propia.

En la Figura 9, se pueden observar el tipo de abonaos aplican los agricultores a los cultivos, el $44 \%$ de agricultores que no hacen uso de los abonos orgánicos y el $9 \%$ aplican estiércol animal, coincidiendo con las Parroquias Guanando, San José de Chazo, San Isidro, San Gerardo que proponen el desarrollo y manejo de la agroecología con huertos familiares (CESA, 2019).

\section{Figura 9}

Tipo de abonos TIPOS DE ABONOS

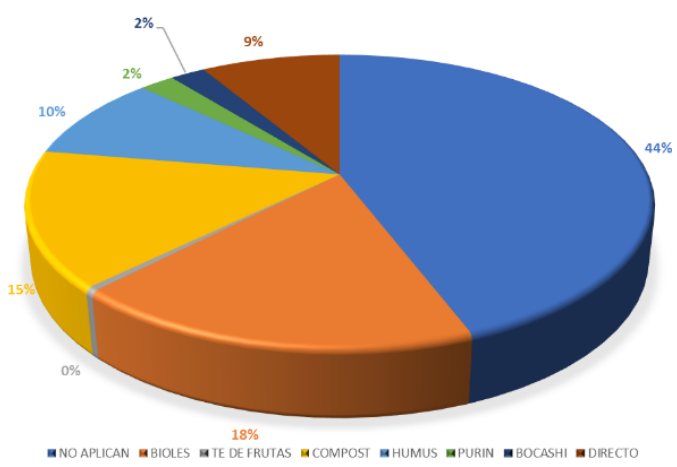

Fuente: Elaboración propia. 


\section{PRINCIPALES PRODUCTOS AGRÍCOLAS DEL CANTÓN GUANO.}

Se midió el parámetro del número de agricultores por producto del Cantón Guano, segmentado en tubérculos, hortalizas, leguminosas y frutas, la Figura 10, indica que existe una producción importante de papa donde 108 agricultores de las Parroquias Ilapo, Santa Fe de Galán, San Andrés y San Isidro se dedican a este cultivo los cuales el 85\% en sacos de $100 \mathrm{lb}$ y el $20 \%$ en canastas que se comercializan en ferias directas al consumidor en los mercados de Riobamba, a estos mismos mercados va la producción de 15 agricultores e oca, comercializado el $9 \%$ de la producción en sacos de $100 \mathrm{lb}$, mientras que el $6 \%$ en porciones.

También se puede observar que existen 5 productores de mashua que se comercializa en porciones por medio de Ferias directas al consumidor. La producción de melloco es proveniente de las Parroquias San Andrés, San Isidro, La Providencia, Ilapo, Valparaíso, San José de Chazo, el 17\% de su comercialización es en sacos de 99 lb hacia el Mercado Mayorista de Riobamba, y Ambato y hacia mercado del Cantón Mocha, mientras que el $6 \%$ de la producción se presenta en porciones hacia las comercializaciones directas en ferias

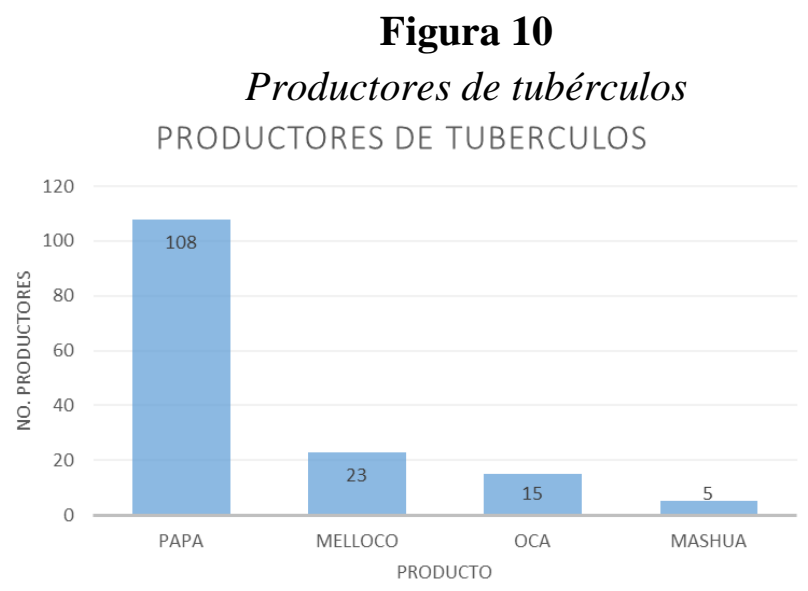

Fuente: Elaboración propia.

La Figura 11, presenta la producción de leguminosa, dentro de las que presenta mayor número de productores se encuentran el haba con 85 de agricultores y el maíz que tiene 81 agricultores lo cultivan, seguido por 72 agricultores dedicados a arveja, 37 de agricultores a la producción de cebada, 20 a producción de chocho, el 5 a trigo, 10 a guarango y finalmente el 40 de agricultores encuestados se dedican a la producción de alfalfa.

La producción de haba es proveniente de las Parroquias Ilapo y Santa Fe de Galán, el 63\% de se comercializa a mercados de Tungurahua: Cantón Mocha y Mercado Mayorista de Ambato y hacia Mercados de Riobamba en presentaciones de $65 \mathrm{lb}$, el $4 \%$ se comercializa en canastas en ferias directas y el $28 \%$ de su producción se comercializa directamente en porciones en huertos familiares, 
La producción de maíz amarillo seco y fresco es provenientes de las Parroquias San José de Chazo, Ilapo, y Valparaíso, el 12\% se comercialización en sacos de 100 lb a mercados de Tungurahua: Cantón Mocha, Mercado Mayorista de Ambato y a Mercados de Riobamba, el $15 \%$ en porciones y el $8 \%$ en ferias directas en canastas,

La producción de arveja se comercializa el 13\% de en sacos de 110 lb hacia mercados de Tungurahua en el Cantón Mocha y Mercado Mayorista de Ambato y el 43\% de la producción hacia mercados de Riobamba en sacos de $43 \mathrm{lb}$, finalmente el $14 \%$ de su producción lo comercializan de forma directa en ferias en porciones, provenientes de las Parroquias San José de Chazo, Ilpo, y Valparaiso.

Con el análisis de la información arrojada se tiene que en el cantón Guano por su parte tiene un importante aporte a la producción agropecuaria provincial, en alfalfa, comercialización en cargas y porciones representadas por el 14 y $26 \%$ proviene de la Parroquia Guanando para la comercialización directa solo en semilla. Con el análisis de la información levantada en el Cantón Guano se obtuvo el siguiente resultado en el porcentaje de comercialización y presentación en el cultivo de cebada con el 33\% de la producción de cebada es para la comercialización en sacos de 100 lb es para los mercados de Riobamba.

Se tiene que el $40 \%$ y $19 \%$ de la producción de pasto en cargas y porciones ratifica la vocación agropecuaria del agricultor que destina el $42 \%$ de sus tierras agrícolas a los pastizales en el Cantón Guano. El cultivo de trigo en un 5\% de la producción de trigo se comercializa en sacos de $100 \mathrm{lb}$ hacia mercados de Riobamba y Mercado Mayorista de Riobamba. Y la avena tiene un $29 \%$ de las comercializaciones a mercados de Riobamba en sacos de $100 \mathrm{lb}$. El 15\% de la producción de chocho son destinadas a la comercialización para los mercados de Riobamba en quintales, mientras que el 5\% de la producción se presentan en porciones y se comercializan en ferias directas organizadas por los mismos agricultores. Y en el cultivo de guarango se tiene que, el 15\% de la producción de Guarango son comercializados en sacos de $60 \mathrm{lb}$ hacia mercados de Riobamba para la industrialización de esta.

Figura 11

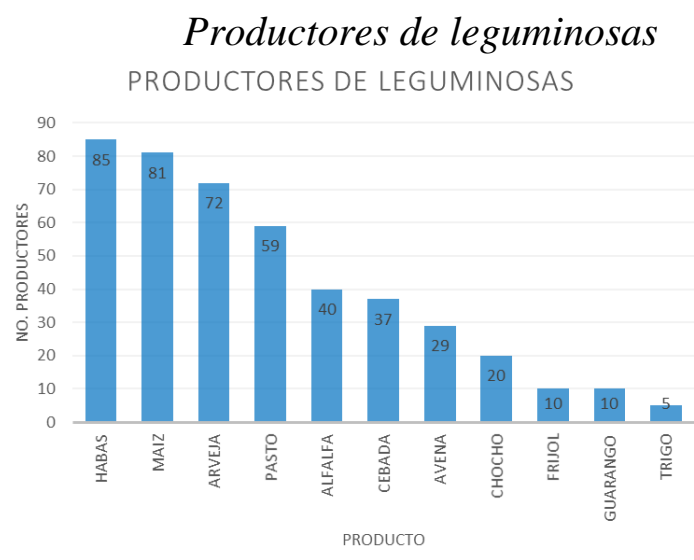

Fuente: Elaboración propia. 
La Figura 12, muestra los productores de hortalizas, en monocultivos en Santa Fe de Galán, 65 agricultores se dedican a la producción de cebolla blanca en rama, así como en la comunidad La Silveria en la Parroquia San Andrés se dedican a la producción del monocultivo de zanahoria amarilla con el mismo porcentaje.

Figura 12

Productores de hortalizas

PRODUCTORES DE HORTALIZAS

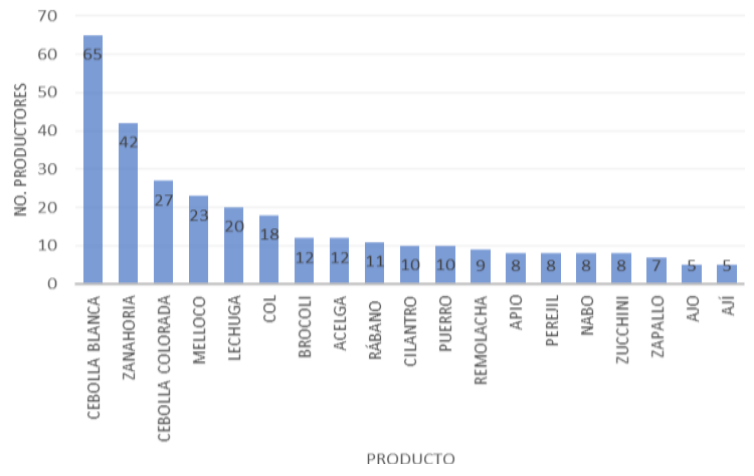

Fuente: Elaboración propia.

El 53\% de la producción de cebolla blanca en rama se comercializa en atados de 4,25 lb hacia Mercado Mayorista de Riobamba y hacia Mercados de Tungurahua en el Cantón Mocha y Mercados Mayoristas de Ambato, el 6\% de la producción en atados de 1 kilo son para la comercialización directa en huertos familiares formando parte de las canastas familiares.

El 33\% de la producción de zanahoria amarilla se comercializa en saco de 100 lb hacia mercados del Cantón Mocha y Mercado Mayorista de Ambato y hacia mercados de Riobamba, el 9\% de la producción se los presenta en porciones hacia comercializaciones directas en ferias, provenientes de las Parroquias San Andrés, San Isidro, y la zona alta de Guano.

El 3\% de la producción de cebolla colorada es para la comercialización hacia mercados de Tungurahua hacia el Cantón Mocha y Mercado Mayorista Ambato en presentaciones de malla de $100 \mathrm{lb}$, el 14\% hacia mercado Mayorista de Riobamba en sacos de 78,5 lb provenientes de las Parroquias San Andrés, San Isidro, en la zona alta de Guano, la Providencia, Ilapo, Valparaíso y San José de Chazo, y el 10\% a la comercialización directa en huertos familiares formando parte de las canastas familiares ofrecidas por los agricultores.

El 12\% de producción de durazno lo comercializan en cajas de 25 kilos hacia mercados de Riobamba, el 6\% de la producción se presenta en canastas siendo comercializadas en ferias directas al consumidor.

El 6\% de la producción de lechuga se comercializa en sacos de 81,25 lb, hacia mercados de Riobamba y mercados de Tungurahua al Cantón Mocha y Mercado Mayorista de Ambato, procedentes de las parroquias San Andrés, San Isidro, y la Matriz zona alta, San 
José de Chazo, La providencia, Ilapo y Valparaíso. El 4\% y $10 \%$ de la producción restante es destinado a la comercialización directa en huertos familiares a través de los mismos agricultores presentados en canastas y en porciones.

El 4\% de la producción de la col se comercializa hacia Mercado Mayorista de Riobamba, mercados Mayorista de Ambato y mercado del Cantón Mocha, en sacos de 107,5lb, producidas en las parroquias San Isidro, San Andrés, San José de Chazo, Ilapo, Valparaíso, el 13\% de la producción de la col forma parte de las canastas orgánicas comercializadas en huertos familiares provenientes de la Parroquia La Providencia.

El 7\% de las comercializaciones de brócoli son en kilos hacia mercados y tiendas de Riobamba y el $4 \%$ de la producción forma parte de las canastas que son comercializadas de manera directa en huertos familiares.

El 2\% de las comercializaciones de acelga son en atados hacia mercados y tiendas de Riobamba, mientras que el $10 \%$ de la producción forma parte de las canastas en las comercializaciones directas en huertos familiares.

El 3\% de la producción de rábano forma parte de la canasta familiar comercializada en huertos familiares de cada agricultor simultáneamente y hacia mercados de Riobamba, mientras que el $8 \%$ se comercializa en porciones por medio de ferias.

En el cultivo de frijol podemos manifestar que, el $10 \%$ de la producción de frijol, se comercializa directamente en porciones en ferias organizadas en el Cantón Guano.

El 8\% de las comercializaciones del cilantro son en kilos hacia mercados de Riobamba, el 5\% de la comercialización se las realiza en porciones directamente en huertos familiares.

El 8\% de la producción de frutilla se los comercializa en cajas de 15 lbs hacia Mercado Mayorista de Riobamba provenientes principalmente de la Parroquia Valparaíso, y el 2\% de la producción son en presentaciones en canastas en comercializaciones directas en ferias.

El 7\% de la producción de cebolla puerro se comercializa en atados de 4,25 lb hacia los mercados de Riobamba y Mercado Mayorista, el 3\% de la hortaliza forma parte de las canastas orgánicas comercializadas en huertos familiares.

El 5\% de la comercialización en remolacha son en sacos de $100 \mathrm{lb}$ hacia mercados de Riobamba El $6 \%$ de la producción de apio son para la comercialización hacia los mercados de Riobamba en kilos, mientras que, el $2 \%$ de la producción son en porciones para ser comercializadas directamente en huertos familiares. El 5\% de la comercialización de perejil es hacia los mercados de Riobamba en kilos, mientras que el 3\% de la producción en canastas para ser comercializadas directamente en huertos familiares y ferias. 
El 8\% de la producción del nabo es comercializa en kilos hacia mercados de Riobamba y hacia Mercados de Tungurahua al Cantón Mocha y Mercado Mayorista de Ambato.

Con la información obtenida mediante las encuestas y entrevistas aplicadas a los agricultores del El 8\% de la producción de zucchini se comercializa en porciones por el momento en Ferias y huertas agroecológicas directamente al consumidor. El 7\% de la producción es para la comercialización del Zapallo es porciones, por medio de Ferias y huertas familiares directas al consumidor. El 2\% la producción de ajo se comercializa en sacos de 50 kilos hacia mercados de Riobamba y el 3\% de la producción son comercializados en porciones por medio de tiendas y en ferias organizadas. Y en la producción de ají, el $2 \%$ se comercializa en sacos de 15 kilos hacia mercados de Riobamba y el 3\% de la producción son comercializados directamente en porciones por medio de ferias organizadas.

La Figura 13, muestra la producción de frutales, se puede observar que los que tienen mayor número de productores son el tomate de árbol, durazno, limón, mora con 29, 22, 20 y 17 productores respectivamente y el menor número de productores para manzana, frutilla, claudia, capulí, uvilla, pera, aguacate y tuna. El 3\% de la producción de Aguacate la comercializa es en sacos de 25 kilos hacia mercados de Riobamba y el $2 \%$ de la producción son comercializadas directamente en porciones por medio de ferias organizadas.

El 24\% de la comercialización en tomate de árbol es en sacos de 85 lb hacia el Mercado Mayorista Riobamba, mientras que el 5\% de las presentaciones es en canastas para la comercialización directa en ferias organizadas por los agricultores.

El 10\% de la producción de la mora se los comercializa en cajas de 8 lbs hacia el Mercado Mayorista de Riobamba, el $7 \%$ de las presentaciones en canastas son comercializadas directamente por los agricultores en ferias. El 7\% de la producción de manzana se comercializa en cajas de 30 kilos hacia los mercados de Riobamba provenientes principalmente de la Parroquia La Providencia, el 6\% de las presentaciones en canastas son comercializadas por medio de ferias internas.

\section{Figura 13}

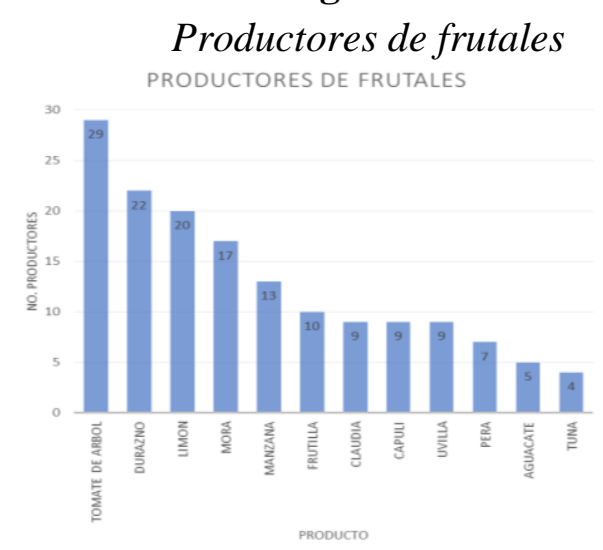

Fuente: Elaboración propia. 
En la comercialización de la Tuna el 3\% se tienen presentaciones en kilos hacia los mercados de Riobamba y el $1 \%$ de la producción en canastas comercializadas hacia ferias directas organizadas internamente.

El 12\% de la producción de limón se comercializa en mallas de 80 lb hacia mercados de Riobamba, y el $8 \%$ de la producción su presentación es en porciones para comercializar directamente en ferias. El 6\% de la producción de Claudia son comercializados en cajas de $20 \mathrm{lb}$ hacia mercados de Riobamba y mercado Mayorista de Riobamba y el 3\% de la producción es en canastas hacia ferias directas del agricultor.

El 6\% de la producción de Capulí se lo comercializa por canastas y el 3\% de la producción son comercializadas en porciones hacia las ferias y mercados de Riobamba. El 7\% de la producción de uvilla son comercializados en canastas y el $2 \%$ comercializada en porciones hacia ferias directas a los consumidores, y a Mercados de Riobamba. Y el 4\% de la producción de la Pera es comercializada en canastas en Ferias directas al consumidor.

\section{E. ANÁLISIS EL COMPORTAMIENTO DEL COMERCIO ELECTRÓNICO EN EL MARCO DE LA PANDEMIA COVID 19.}

En las Figura 14, se un análisis de los productores del Cantón Guano referente al componente tecnológico se puede ver que el $34 \%$ de los encuestados conocen del manejo de una página web, en el Cantón Guano el 9,78 \% de la población son adultos mayores que van entre 46 - 83 años concentrados en la parroquia Guano, La Matriz, El Rosario, en la Parroquia San Andrés y San José de Chazo, representando el $66 \%$ de los agricultores encuestados (CESA 2019).

El $85 \%$ de los agricultores encuestados no conocen del uso del comercio electrónico por falta de conocimiento en alternativas para la comercialización en la compra y venta vía on line en productos de interés y el $15 \%$ de los beneficiarios saben del uso del comercio electrónico, en vista de que la edad fluctúa entre los 16 a 23 años los mismos que tienen acceso a teléfonos inteligentes y acceso a la interconectividad como computadora y redes sociales.

\section{Figura 14}

Análisis del componente tecnológico TECNOLOGÍA

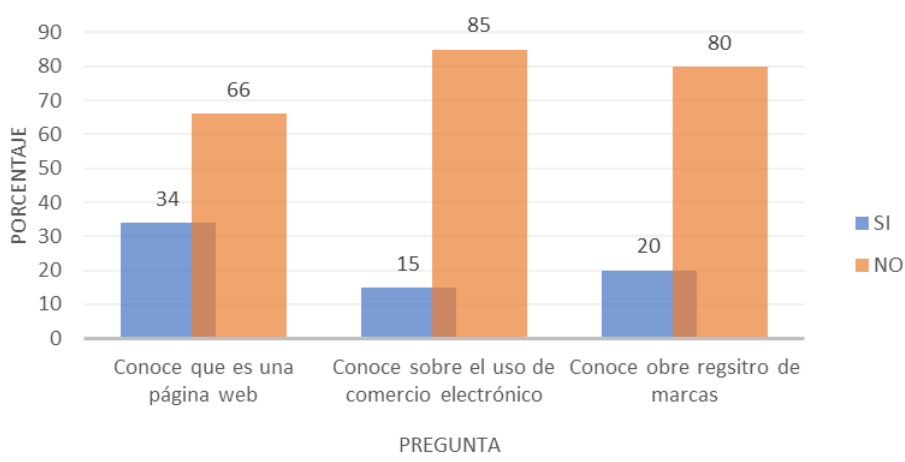

Fuente: Elaboración propia. 
De acuerdo con el análisis realizado luego del trabajo recopilado en campo durante las encuestas se concluye que, el $20 \%$ de los agricultores encuestados si conocen de marcas registradas y el $80 \%$ de los datos analizado no conocen de marcas registradas, como La Ibérica, Supermaxi, entre otras, por la falta de conocimiento en el manejo de las plataformas y redes sociales, por lo general los adultos mayores son los que carecen de esta información por desinterés, tiempo o accesibilidad al internet.

La Figura 15, muestra que el $37 \%$ de los agricultores hacen uso de la plataforma Whatsapp las que edades que fluctúan entre 25 a 55 años, considerado como uso exclusivo por temas educativos, seguido del $28 \%$ de encuestados utilizan la plataforma Facebook con edades que fluctúan entre 25 a 48 años y el $29 \%$ de agricultores no utilizan ningún medio de comunicación virtual sea por el desinterés en el uso de redes sociales o la falta de acceso a internet y equipos informáticos como computadoras o teléfonos inteligentes.

Figura 15

Uso de redes sociales

USO DE REDES SOCIALES

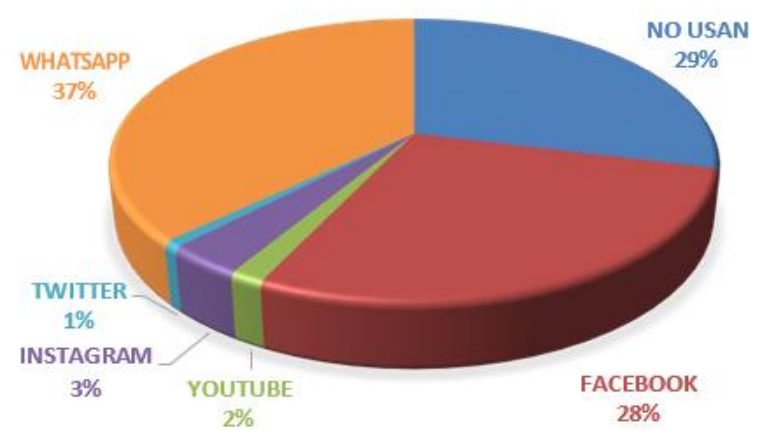

Fuente: Elaboración propia.

\section{Análisis de la Demanda Insatisfecha}

Basado en el mercado que no esté siendo cubierto o abastecido y con la participación virtual con la aplicación de las entrevistas en línea o telefónica y presencial aplicando las encuestas en forma directa de acuerdo con una hoja ruta preestablecida con los técnicos del GAD Municipal con la Unidad de Aprendizajes y Emprendimientos juntamente con los presidentes de las Juntas Parroquiales para cubrir con el levantamiento de información.

Para el respaldo en la producción para la oferta y comercialización a través de la plataforma virtual se puede apreciar en la Figura 16 el porcentaje de productores satisfechos con sus producciones. 
Figura 16

Productores satisfechos con la comercialización PRODUCCION SATISFECHA

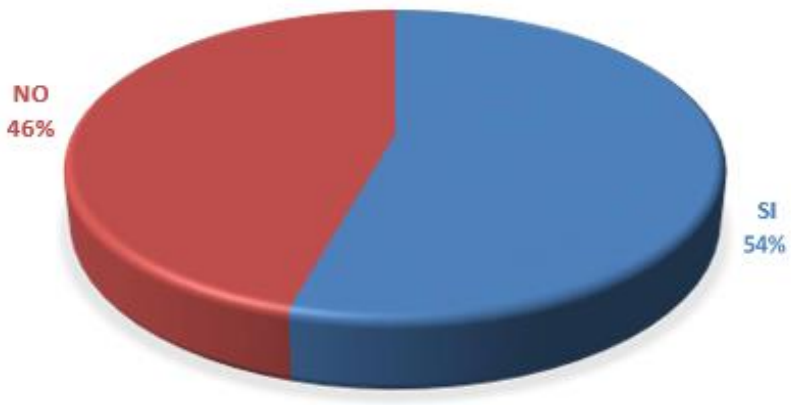

Fuente: Elaboración propia.

El $54 \%$ de los agricultores encuestados manifiestan su satisfacción en la producción agrícola, porque tienen cantidad de productos permanentes precisamente los cultivos que se asientan entre los 2.600 y $3.300 \mathrm{msnm}$, no obstante, encuentran desagrado al momento de comercializar su producción por la presencia de intermediarios en los Mercados Mayoristas donde comercializan sus productos que son los que duplican el precio de los productos perdiendo económica los agricultores directos.

El canal de comercialización manejado por los productores del Cantón Guano se puede apreciar en la Figura 17, los mismos serán beneficiarios para la comercialización de sus productos a través de la plataforma virtual.

El estudio indica que el $49 \%$ corresponde a hacia Mercados de Tungurahua en el Cantón Mocha y en Mercado Mayorista de Ambato y Mercados de Riobamba, principalmente provenientes de las Parroquias Ilapo y Santa Fe de Galán San José de Chazo, Valparaíso, San Andrés, San Isidro, Guano zona alta, lo que concuerda con el informe final realizado por (CESA 2019). Y el $5 \%$ y $12 \%$ corresponde a los agricultores que comercializan directamente sus productos en ferias y huertos familiares organizados internamente ya que la comercialización lo hacen en forma rotativa una vez por semana en visita de los huertos de los diferentes beneficiarios provenientes de la Parroquia La Providencia, como caso particular, mientras que el $10 \%$ de los encuestados la comercialización lo realizan a través de intermediarios en tiendas de barrio, finalmente el $24 \%$ de los agricultores encuestados su producción es utilizado para su autoconsumo, por los bajos rendimientos o la tenencia de la tierra que hace que se produzca una diversificación de productos sin garantizar la producción constante para el exceso comercializado 


\section{Figura 17}

Canales de comercialización

Canal de comercialización agrícola

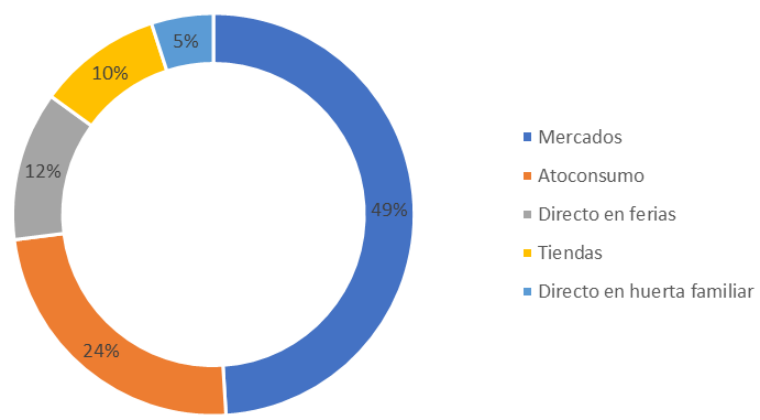

Fuente: Elaboración propia.

\section{F. MODELO DE NEGOCIO PARA LA COMERCIALIZACIÓN DE PRODUCTOS AGRÍCOLAS Y DERIVADOS DEL CANTÓN GUANO.}

Para definir el modelo de negocio es importante realizar el análisis d FODA, un plan de capacitación, una estrategia de comercia, los cuales se describen en este apartado.

\section{Análisis FODA}

El análisis FODA se muestra en la Figura 18, este proporciona una perspectiva de la situación interna, incluidas las fortalezas y debilidades y un entorno externo compuesto de oportunidades y amenazas (Ballesteros et al. 2010).

\section{Figura 18}

\section{Matriz FODA}

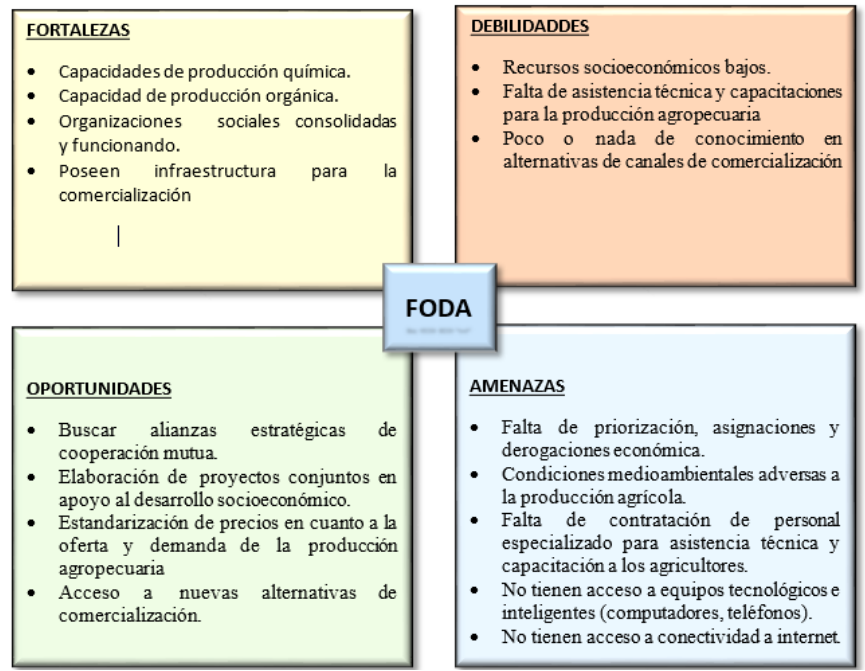

Fuente: Elaboración propia.

Para lograr definir un modelo de negocio en apoyo al agricultor y su comercialización en productos agrícolas y derivados fue necesario hacer un análisis FODA en el cual las 
fortalezas identificadas se pueden convertir en oportunidades, mientras que las debilidades se pueden trasformar en amenazas para la ejecución del proyecto.

\section{Diseñar un Plan de Capacitación en Comercio Electrónico}

Como parte de los protocolos desarrollados para la implementación de la plataforma de comercio electrónico para la Agricultura Familiar Campesina post Covid 19, se plantea un plan de capacitación dirigida a técnicos de la Unidad de Tics del GAD Municipal Guano quienes manejaran la plataforma, para garantizar la ejecución del buen uso y manejo de la plataforma propuesta, de igual manera se propone la capacitación a los líderes o lideresas de cada Parroquia para que puedan ofrecer sus productos en cantidad y calidad. Así como también a los beneficiarios o usuarios de la plataforma previo registro.

\section{Diseño de Modelo de Negocio para los Productores del Cantón Guano}

Se definió que los modelos de negocios a analizar deberían permitir que productores de la Agricultura Familiar Campesina (las empresas) pudiesen comercializar productos definidos como campesinos a los consumidores (los clientes). Aunque los clientes pueden ser empresas privadas o del gobierno. La propuesta de diseño de modelo de negocio para ser replicado en el proyecto "Propuesta de comercio electrónico para la agricultura familiar campesina del Cantón Guano en el contexto de la pandemia Covid 19”, se basa en el patrón identificado al modelo del tipo B2C (Empresa a Consumidor) propuesta por INDAP 2016.

\section{Diseño de Estrategias de e-commerce}

Garantizar la producción en cantidad y calidad para asegurar la comercialización mediante la creación de las ECAs (Escuelas de Campo), se aplicará los protocolos establecidos de experiencias y lecciones aprendidas de proyectos de similares características desarrollado también en este trabajo. Para el diseño de modelo de negocios se aplicará la estructura general que se muestra en la Figura 19.

\section{Figura 19}

Diseño de Estrategias de e-commerce

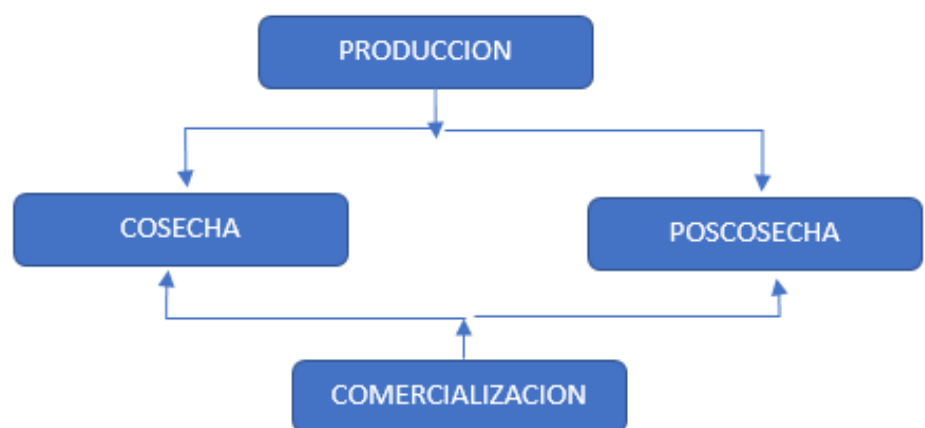

Fuente: Elaboración propia. 
La propuesta realizada para la ejecución del proyecto " Propuesta de comercio electrónico para la agricultura familiar campesina del Cantón Guano en el contexto de la pandemia Covid 19“ está basada en, producción.

PRODUCCIÓN: la propuesta está basada en la producción en cantidad y calidad de cada uno de los productores del Cantón Guano, siempre y cuando se le participe en dar asistencia técnica, capacitaciones y seguimiento desde la siembra hasta la cosecha, esta está directamente relacionada con, cosecha.

COSECHA: con el buen manejo de la producción se llegará a estándares de calidad como es el tamaño, sabor, sanidad de los productos a comercializar lo que garantizará la sanidad y el bueno producto que llegue a la mesa del consumidor, dentro de la propuesta está diseñado el manejo universal que viene de la mano que es, poscosecha.

POSCOSECHA: la propuesta está basada desde la utilización del lavado, desinfectado del producto, clasificado, pesado y embalado de acuerdo con el producto priorizado en el proyecto, es importante manejar el valor agregado en la plataforma mediante fotografías y presentaciones de los productos terminados para el consumidor que termina en la propuesta con la comercialización.

COMERCIALIZACION: la propuesta de la plataforma empieza a funcionar con una guía electrónica en apoyo al productor basándose en el registro básico de datos personales, empezando a formar parte de los beneficiarios en el proyecto, seguido de la selección de los cultivos producidos por el agricultor, la formación de canastas familiares, con esto se ira generando una base de datos para ser visualizado a nivel nacional ya que estará formando parte de uno de los servicios brindados en la página web del GAD Municipal Guano, el consumidor tendrá acceso a la plataforma para adquirir los productos ofertados mediante un acceso directo que les llevara directamente a la plataforma en donde podrán seleccionar el o los productos deseados los cuales cada uno de ellos tendrán la información sobre quien produce, lugar de procedencia y numero de contacto el cual será el medio por el cual el consumidor y productor harán la compra y venta directa, se recalca que el GAD Municipal y/o Administrador de la Plataforma no interviene en valores monetarios de venta ya que el fin de la propuesta es apoyar al productor en otras alternativas innovadoras de comercialización para sumar a la activación económica del Cantón Guano, eliminando también a los llamados intermediarios.

\section{Resultados.}

Se identificó el comercio clásico o tradicional exclusivamente de una tienda virtual o una extensión de la tienda física manejándose bajo la modalidad en la compra del producto (artesanía en lana) y la venta a sus clientes.

Tomando en consideración que este accionar no es solo a nivel virtual, siendo lo contrario en la comercialización para productos agrícolas basándose solo en la compra y venta presencial con el peor de los casos la presencia de los llamados intermediarios, alterando el valor monetario para el agricultor y consumidor. 
Lo que se concluye el vacío en alternativas de comercio electrónico para productos campesinos y la búsqueda de un comercio justo para los productores del Cantón Guano. La selección aleatoria simple permitió encuestar a 185 agricultores personalmente.

En el comportamiento de consumidores y productores en tiendas virtuales en el marco de la pandemia COVID 19, se pudo diferenciar claramente que el modelo de negocio manejado por los productores agropecuarios en el Cantón Guano está basado en el modelo del tipo B2C (Empresa a Consumidor) con el patrón identificado para el Cantón Guano de comerciante clásico, haciendo referencia a la Asociación de mujeres tejedoras de Pulingui. Ubicadas en la Parroquia San Andrés corresponde a las tiendas electrónicas clásicas, y consiste en la compra y venta online de bienes o servicios mediante un catálogo digital. Puede tratarse de una tienda exclusivamente digital o ser una extensión de una tienda física real.

\section{Diseño de la plataforma de comercio electrónico}

"aun clic de tu cosecha" se diseñó en base a los resultados de la investigación de tal forma que pueda ayudar a la Agricultura Familiar Campesina, para la reactivación económica en tiempos de pandemia, brindándoles la oportunidad de un comercio justo y a la vez que los consumidores puedan acceso directo a variedad de productos frescos y calidad.

Mantiene dos perfiles, el usuario donde el consumidor puede interactuar con el productor y el administrador para otro poder ingresar los datos de los productores.

\section{Perfil usuario}

La Figura 20, muestra el recorrido de la página web al público, que se puede acceder a través del enlace https://tucosechaclic.com, para acceder a la página web.

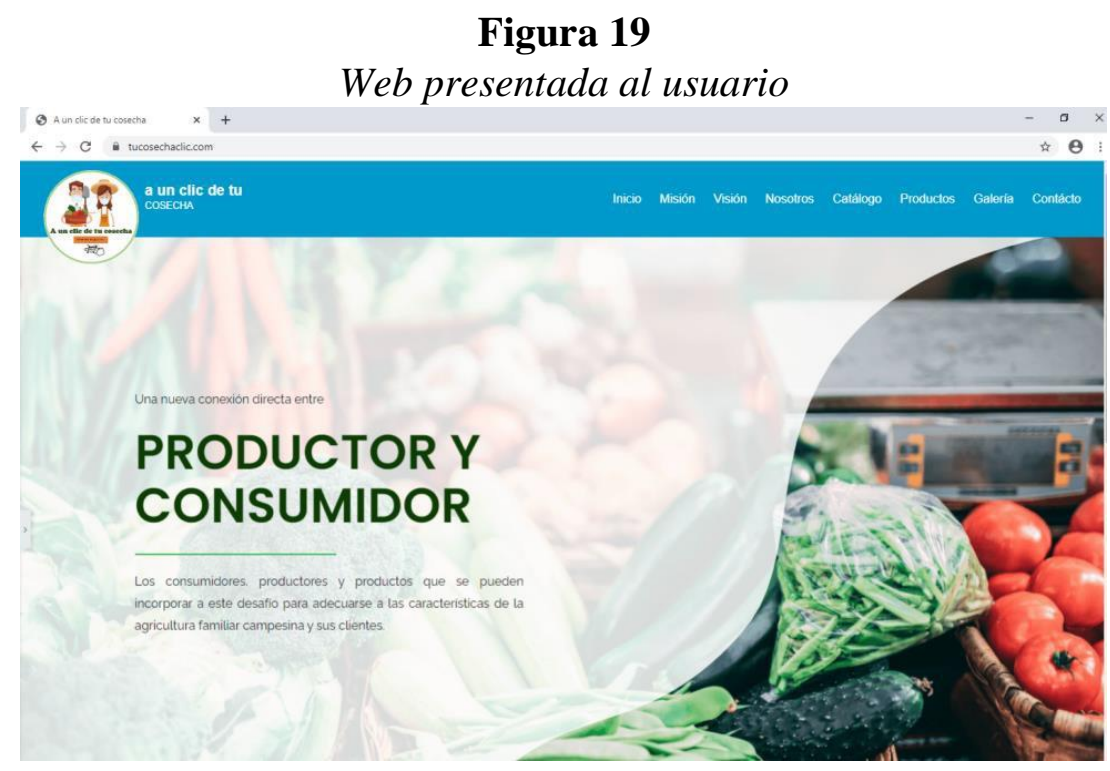

Fuente: Elaboración propia.

Presenta un menú para poder visualizar la Misión y la Visión de la web, el menú Nosotros 
que despliega información sobre el propósito de la página

La galería que es un espacio para incorporar imágenes de actividades que se realicen en beneficio del productor, asistencia técnica, capacitaciones y otras actividades referentes a la comercialización.

El Catálogo se muestra en la Figura 21, donde podemos observar productos agrupados por categoría.

\section{Figura 21 \\ Menú Catalogo}
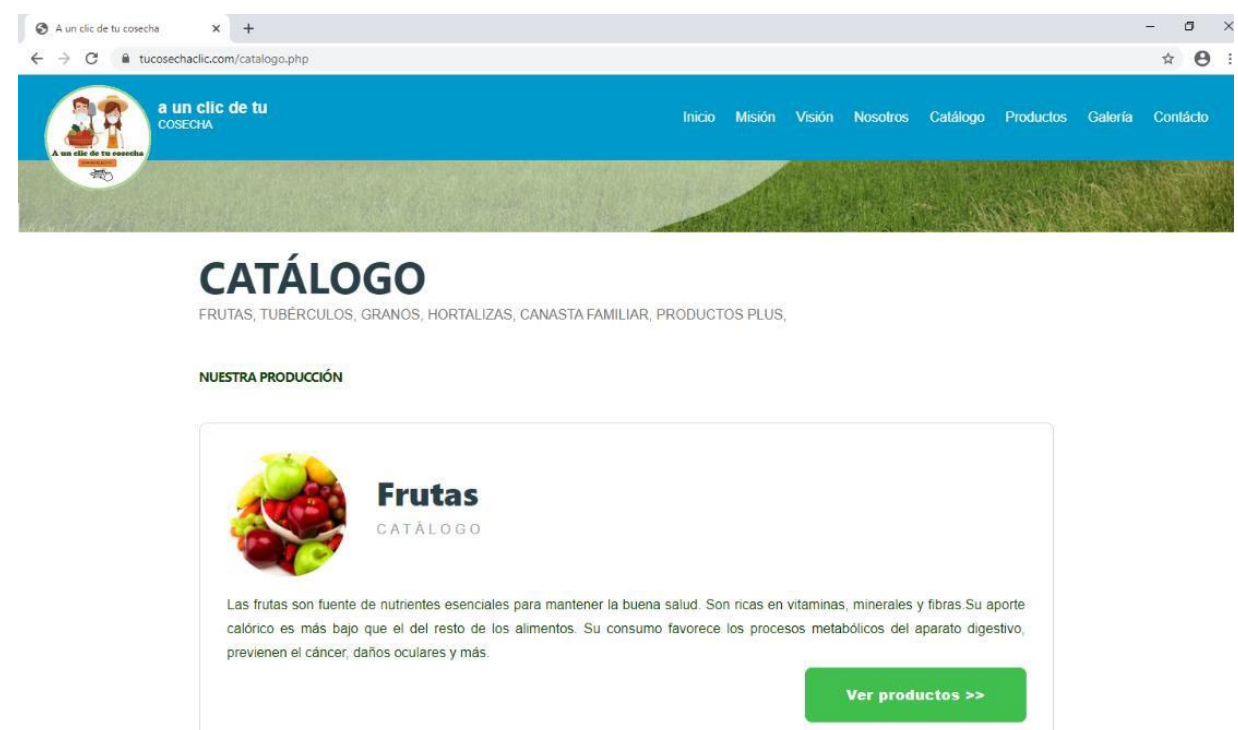

Fuente: Elaboración propia.

El menú Productos se observar en la Figura 22, qui se presenta la información de los productos, e información del productor.

Figura 22

Menú de Productos
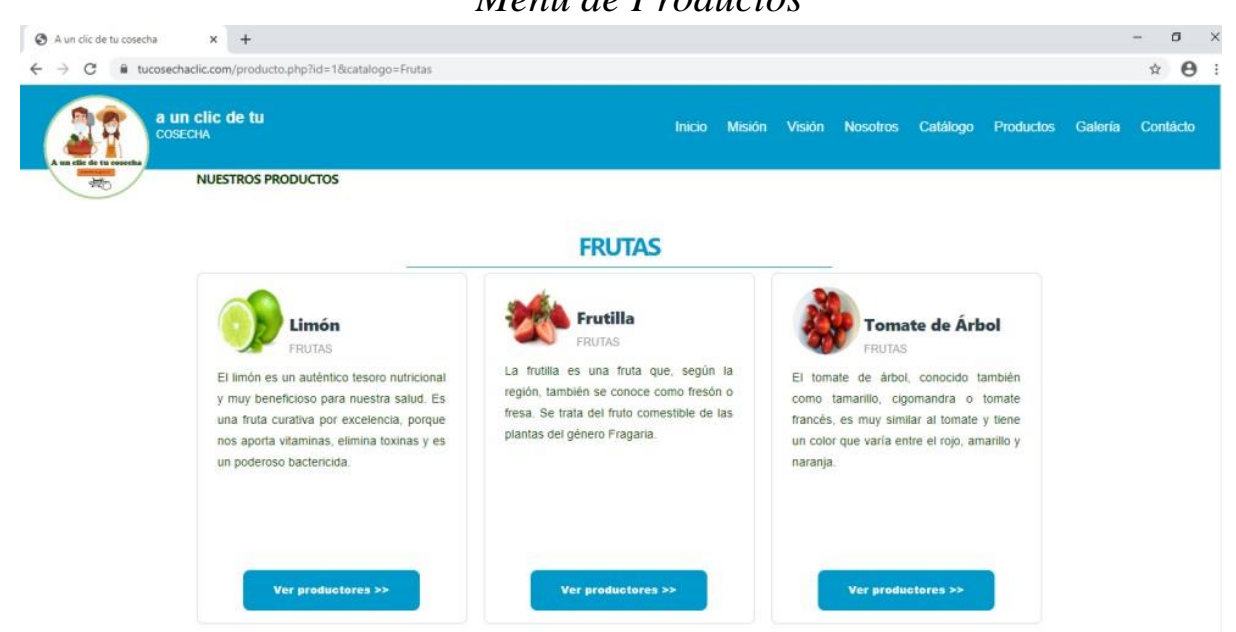

Fuente: Elaboración propia.

En espacio Contacto tiene la finalidad de ingreso y registro a nuevos productores, el 
contacto de soporte técnico para socios y el mail de administración para reportar cualquier novedad.

\section{Perfil Administrador}

La Figura 23 muestra el perfil administrador se accede por el url: https://tucosechaclic.com/administrar/, luego de solicita usuario y contraseña.

Figura 23

\section{Perfil administrador}

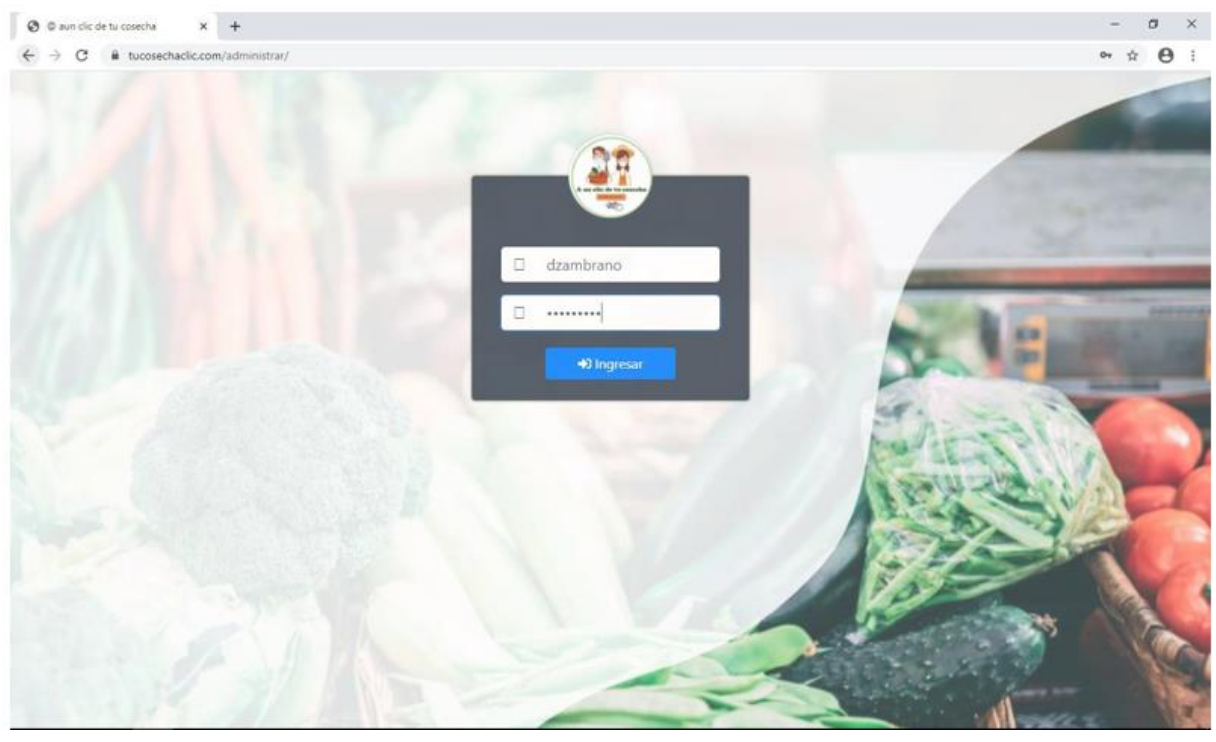

Fuente: Elaboración propia.

Una vez permitido el ingreso se presenta la pantalla de la Figura 24.

El menú Catálogos presenta un listado de su respectiva información, en la columna catalogo se describe los grupos en que estarán divididos los productos ofertados por cada productor, en la columna que indica descripción se detalla las características de cada grupo de productos que forman parte de dicho catálogo, en la columna de imágenes se insertara fotografías reales de lo ofertado, también se puede editar o eliminar los productos ofertados.

El menú Productos permite ingresar, eliminar, modificar los productos.

El Menú Servicios, nos visualizará la información respectiva, que tiene asignado un Productor con los productos que oferta.

El Menú Galería, aquí podremos tener la información de las imágenes para la respectiva galería. Y el Menú Cerrar Sesión, nos redirecciona a la página principal web. 


\section{Figura 24}

Web para administrador

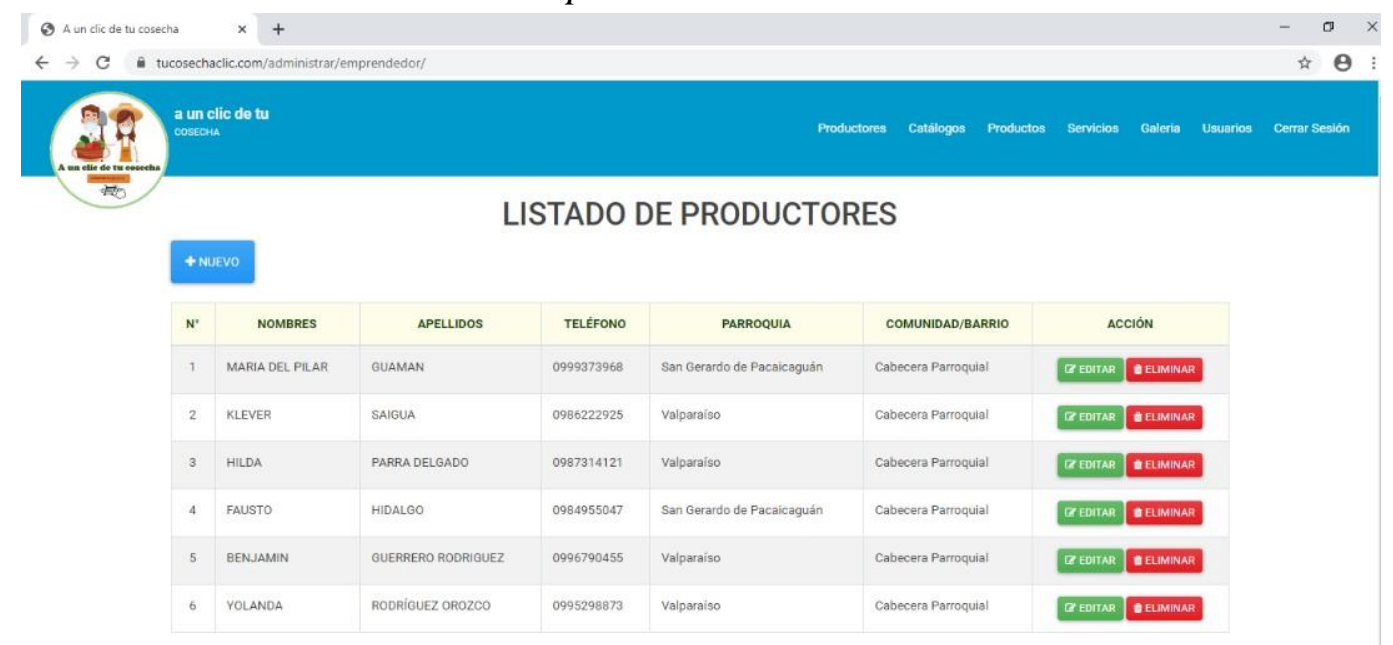

Fuente: Elaboración propia.

\section{Conclusiones.}

- La implementación de la plataforma "a un clic de tu cosecha" garantizara, el manejo de una agenda virtual en la que constara el listado de productores asociados y con sus respectivos productos a comercializar.

- Con la implementación de la plataforma "a un clic de tu cosecha" le garantiza al productor y/o emprendedor comercializar sus productos con valor agregado y precio justo.

- A través de la plataforma "a un clic de tu cosecha" se promueve para que el agricultor forme parte de la comercialización de productos que cubren la formación de las canastas familiares.

- Se concluye que el modelo de negocio de mayor factibilidad en la zona de estudio en el cantón Guano, es el modelo del tipo B2C (Empresa a Consumidor) que más se adapta a la comercialización el mismo que hace referencia a la compra y venta entre el productor y consumidor final.

- El comerciante clásico actualmente se encuentra rezagado por efectos de la pandemia que les impidió para su comercialización el contacto directo entre el productor y consumidor, hoy por hoy está en boga la implementación y comercialización en plataformas virtuales, "a un clic de tu cosecha" es el cumplimiento del primer objetivo de la investigación.

- Asegurando la producción en calidad y cantidad con productos que cubren la soberanía alimentaria, el agricultor está en capacidad de comercializar en tiendas virtuales aprovechándose de la conectividad que tienen acceso en el campo.

- Con la producción y comercialización mediante tiendas virtuales de alguna manera ayuda a estandarizar los precios entre productor y consumidor ya que se evita de intermediación. 


\section{Agradecimientos.}

Al Ilustre Municipalidad de Guano por su apoyo y colaboración en este proyecto, a más de ser quienes avalaron la plataforma "a un clic de tu cosecha" para su implementación en el cantón Guano.

\section{Referencias bibliográficas.}

Ballesteros, Haydée, Josefina Verde, Miriam Costabel, Rosa Sangiovanni, Iris Dutra, Diana Rundie, Fiorella Cavaleri, y Lorena Bazán. 2010. «Análisis FODA: Fortalezas, Oportunidades, Debilidades y Amenazas.» Revista Uruguaya de Enfermería 5(2).

CESA. 2019. Actualización del plan de desarrollo y ordenamiento territorial del cantón Guano.

CLACSO. 2021. «Pensar la Pandemia». CLACSO. Recuperado 10 de agosto de 2021 (https://www.clacso.org/pensar-la-pandemia-observatorio-social-delcoronavirus/).

Comunicacion, Departamento. 2021. «ESPOCH CONECTA AL PRODUCTOR Y CONSUMIDOR - Escuela Superior Politécnica de Chimborazo». Recuperado 10 de agosto de 2021 (https://www.espoch.edu.ec/index.php/component/k2/item/5273-espochconecta-al-productor-y-consumidor.html).

Esteves, A. 2020. «El impacto del COVID-19 en el mercado de trabajo de Ecuador».

FAO. 2018. «Conferencia regional de la FAO para Europa».

INDAP. 2016. «Desarrollo de un modelo de negocios de comercio electrónico para la $\mathrm{AFC}$.

Nielsen. 2018. «Consumidores conectados».

Perdigón, Rudibel. 2018. «Estrategias de comercio electrónico y marketing digital para pequeñas y medianas empresas».

Rodríguez, K. 2020. «El e-commerce y las Mipymes en tiempos de Covid-19».

Sandoval, Carla. 2020. «Cierres y restricciones en los mercados dificultan el abastecimiento a tiendas y hogares en Quito». El Comercio. Recuperado 10 de agosto de 2021 (https://www.elcomercio.com/actualidad/quito/problemasabastecimiento-tiendas-cierre-mercados.html).

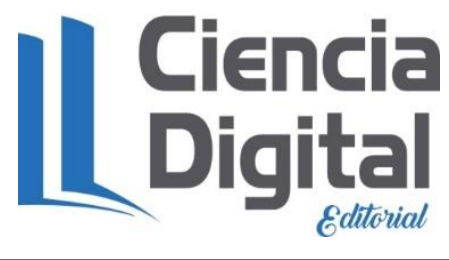




\section{PARA CITAR EL ARTÍCULO INDEXADO.}

Mantilla Cabrera, C. E., Zambrano Ríos, D. A., León Ruiz, J. E., \& Parra León, V. J. (2021). Ciber agricultura familiar en tiempo de COVID 19, contexto Guano- Ecuador. ConcienciaDigital, $\quad 4(3.1)$, 355-380. https://doi.org/10.33262/concienciadigital.v4i3.1.1839

\section{\Ciencia}

El artículo que se publica es de exclusiva responsabilidad de los autores y no necesariamente reflejan el pensamiento de la Revista Conciencia Digital.

El artículo queda en propiedad de la revista y, por tanto, su publicación parcial y/o total en otro medio tiene que ser autorizado por el director de la Revista Conciencia Digital.

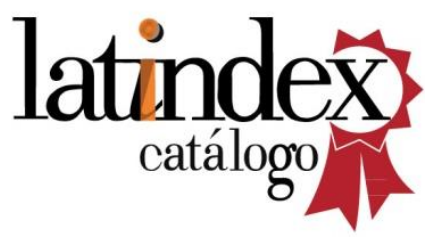

